\title{
Systems-level Barriers in Accessing Supportive Mental Health Services for Sexual and Gender Minorities: Insights from the Provider's Perspective
}

\author{
John McIntyre \\ McMaster University \\ Andrea Daley \\ York University \\ Kimberly Rutherford \\ University of British Columbia \\ Lori E. Ross \\ Centre for Addiction and Mental Health
}

\begin{abstract}
Lesbian, gay, bisexual and transgender (LGBT) people report poorer mental health outcomes than do heterosexual, cisgender (non-trans) people, but little is known about their experiences with mental health services. In this qualitative study, 8 mental health service providers with substantial experience working with LGBT communities were interviewed in order to begin to examine systems-level barriers to supportive mental health services for LGBT people. The results suggest that the medical model, which is pervasive in the mental health system, produces particular access barriers for LGBT people. We offer recommendations for addressing these barriers, including implementing an anti-oppression approach to mental health care.
\end{abstract}

Keywords: lesbian/gay/bisexual/transgender, mental health services, systems-level barriers, medical model, anti-oppression approach

John McIntyre, Department of Psychology, McMaster University; Andrea Daley, School of Social Work, York University; Kimberly Rutherford, Department of Family Medicine, University of British Columbia; Lori E. Ross, Social Equity and Health Research Section, Centre for Addiction and Mental Health.

Correspondence regarding this article should be addressed to John McIntyre at mcintj4@gmail.com 
Until the 1970s, homosexual attractions and behaviours were pathologized by the American Psychiatric Association (APA) through the inclusion of homosexuality as a psychopathological diagnosis in the Diagnostic and Statistical Manual of Mental Disorders (DSM) (Spitzer, 1981). When it was delisted from the DSM-II in 1974, many mental health organizations began to shift away from the illness model of homosexuality towards a more positive approach that placed greater emphasis on quality mental health care (American Psychiatric Association, 1973). As a result, LGBT-affirming providers now focus on working with LGBT people to address the impacts of social discrimination — including homophobia, biphobia, and transphobia — on their mental health (Page, 2004). However, some mental health practitioners continue to focus their research and practice on conversion therapy, in an attempt to repress their clients" "homosexual tendencies" (Page, 2004).

Affirmative mental health services, meaning those that offer a culturally sensitive approach that "affirms a lesbian, gay, or bisexual identity as an equally positive human experience and expression to heterosexual identity" (Davies, 1996, p. 25), are particularly important for LGB people in light of the mental health disparities associated with marginalized LGB communities (Crisp \& McCave, 2007). In a meta-analysis of multiple epidemiological studies, Meyer found that, relative to heterosexuals, LGB respondents experienced increased rates of mood, anxiety, and substance-use disorders (Meyer, 2003). More recently, a meta-analysis conducted by King and colleagues, which pooled the findings of 25 independent research studies including approximately 12,000 LGB individuals, found that LGB individuals experienced almost twice the risk for suicide attempts and 1.5 times the risk for depression and anxiety as did their heterosexual counterparts (King et al., 2008). Although fewer data are available regarding the mental health status of transsexual individuals, the limited research suggests that mental health disparities are also associated with gender minority identities (Clements-Nolle, Marx, Guzman, \& Katz, 2001; Pitts, Couch, Mulcare, Croy, \& Mitchell, 2009).

There is accumulating evidence that discrimination and exclusion experiences associated with sexual minority identities are important contributors to the observed mental health disparities. Mays and Cochran (2001) were the first to report a significant relationship between the effects of discrimination on the basis of minority sexual orientation and mental health status. Examining data collected in the 1995 National Survey of Midlife Development, which considered the responses of 3032 people aged $25-74$, they found that $76 \%$ of LGB individuals - as opposed to $65 \%$ of heterosexual individuals - reported having experienced discrimination (Mays \& Cochran, 2001). Furthermore, perceived discrimination showed a positive association with psychiatric disorders in LGB participants, with a $160 \%$ increase for those reporting a lifetime discriminatory experience and a $21.3 \%$ increase for those reporting day-to-day experiences of discrimination (Mays \& Cochran, 2001). These data are consistent with other research demonstrating a strong relationship between perceived experiences of discrimination and mental health status, not only among LGB people but also for other minority populations (Kessler, Mickelson, \& Williams, 1999; Clark, Anderson, Clark, \& Williams, 1999).

Not surprisingly, there is also evidence that LGB individuals use mental health services more than heterosexuals. For example, a recent Canadian study drawing from two cycles (2003 and 2005) of the Canadian Community Health Survey (CCHS), a national probability survey that included 268,520 respondents, found elevated rates of service use amongst LGB individuals across a variety of provider disciplines including a more than $200 \%$ increase from their heterosexual counterparts (Tjepkema, 2008). No data were found regarding service utilization rates for the trans communities - an outcome which is potentially explained by the more complex relationship between medical service providers and trans 
individuals, who may be accessing mental health services for medical (transition-related) reasons rather than for mental health concerns.

Unfortunately, the high rate of mental health service utilization by sexual minority groups does not appear to be associated with high rates of satisfaction with mental health services. In the only study to date that has measured LGBT satisfaction with mental health services in comparison to a group of heterosexual, non-trans individuals, Avery, Hellman, and Sudderth (2001) examined a small group of LGBT individuals and a comparison group in New York City. Their findings indicate that overall 17.6\% of the 67 LGBT participants were dissatisfied with their mental health services compared to $8.0 \%$ of heterosexual, non-trans participants. This difference was even more pronounced when limited to African American and female participants (Avery et al., 2001). A recent internet-based survey conducted by our research team revealed that over $50 \%$ of LGB and trans-identified people reported unmet need for mental health services. Trans respondents, in particular, reported that they stopped accessing mental health services due to negative experiences (Simeonov, Steele, Anderson, \& Ross, 2011). To date, research in this area has focused on identifying provider-level barriers to mental health care for LGBT clients, including provider lack of knowledge about LGBT-specific issues, heterosexist or genderist ${ }^{1}$ assumptions, and outright discrimination (Israel, et al., 2007).

Canadian research has looked primarily at identifying barriers to health services for LGBT people; more specifically, attention has been given to the issue of access to hospital-based and community-based primary health care (Brotman \& Ryan, 2004; Coalition for Lesbian and Gay Rights in Ontario [CLGRO], 1997; Daley, 1998; Dobinson, MacDonnell, Hampson, Clipsham, \& Chow, 2005; Duncan et al., 2000; Gapka \& Rupert, 2003; Jackson et al., 2006; MacDonnell, 2001a, 2001b; Mathieson, Bailey, \& Gurevich, 2002). The invisibility of LGBT people in primary care health services contexts has been reported to be associated with institutionalized heterosexism, biphobia, and transphobia and also with lack of provider knowledge.

For people identifying as bisexual and/or transgender, barriers to health services may be enhanced due to: (a) an overall lack of understanding and education about bisexuality and transgenderism, (b) judgments being imposed upon them by health care providers, (c) their experiences of limited support and/or acceptance from lesbian and gay communities, and (d) their exclusion from initiatives that aim to address health systems' inequities for sexual minority populations. For example, bisexual women who have been out as lesbians to their physicians have reported feeling "awkward, afraid or uncomfortable" about asking for birth control or safer sex information with men (Dobinson et al., 2005, p. 57). Beyond system-level access barriers to sexreassignment surgery and hormone replacement therapy, transphobia and a lack of transgender-competent clinicians has led to broad-based barriers to substance-use and addiction services, community counselling programs, and other relevant health services (e.g., cancer screening services) for transgender people who are diversely situated based on race/ethnicity, age, income and disability (Gapka \& Rupert, 2003). We were unable to identify any research, however, which specifically investigates the systems-level barriers which likely impact the mental health service access experiences of LGBT people and LGBT affirming mental health service providers.

In summary, limited research, as reviewed above, has examined the experiences of sexual and gender minority individuals in accessing responsive mental health services. However, we were unable to identify other studies that have approached this question from the perspective of mental health service providers and systems-level barriers. Practitioners with extensive experience working with the LGBT communities 
have invaluable experience that can provide insight into potential barriers and in particular can illuminate systems-level factors that may not be apparent to LGBT people using mental health services. The goal of this study is to further understanding of the experiences of sexual and gender minority individuals accessing mental health care, with a focus on identifying potential avenues for systems-level interventions.

\section{METHODS}

\section{Participants}

Participants were identified using the service provider database of Rainbow Health Ontario, a provincewide program that works to promote health and improve access to care for the LGBT communities. The Rainbow Health Ontario database requires: (a) the input of providers' contact information, (b) identification of whether the service provided to residents was direct health or social service, and (c) an assessment of whether or not the provided service was LGBT-positive. In addition, providers must be licensed and/ or certified. Inclusion criteria for our study required that a potential participant: (a) be a practicing mental health professional; (b) have at least two years of experience working with sexual and gender minorities in the context of mental health services (of the eight participants, seven reported having greater than 5 years of practice experience with LGBT populations); and (c) be proficient in English. To identify a diverse participant sample, the researchers consulted with LGBT community leaders in mental health during the participant recruitment process. Attempts were made to recruit participants from across Ontario; however, we were unable to locate potential participants outside of the Greater Toronto Area (GTA) who met the inclusion criteria of at least two years of experience working with sexual and gender minorities within a mental health service context. As such, all participants included in the study practiced within 75 kilometres of the GTA.

Following approval from the ethics review boards at the Centre for Addiction and Mental Health and McMaster University, eight potential participants selected for diversity in age, gender, ethnicity, and type of practice were sent invitations electronically via e-mail. Of the eight individuals who were contacted, all consented to participate.

Participants reported working within a variety of mental health service settings including communitybased centers $(n=3)$, hospital-based centres $(n=2)$ and private practice $(n=3)$. Among the eight participants, four professional disciplines were represented including psychiatry $(n=2)$, psychology $(n=1)$, social work $(n=3)$ and psychotherapy $(n=2)$. The majority of participants were female $(n=5)$, with a minority indentifying as male $(n=3)$, including one trans (FTM) person. Participants identified their sexual orientation as gay $(n=2)$, lesbian $(n=1)$, bisexual $(n=1)$, or queer $(n=4)$, with no heterosexual participants. The majority of participants were Caucasian $(n=6)$, with the exception of one East Asian and one South Asian participant.

\section{Data Collection}

In total, eight one-on-one, semi-structured interviews ranging from one to two hours in length were conducted. One of the co-authors (JM) conducted the interviews between December 2009 and January 2010 at the participants' work places. Written informed consent was obtained prior to each interview. Interviews were recorded using a digital recording device and transcribed verbatim by the interviewer. All personal 
identifying information was removed during transcription, and pseudonyms were assigned to participants at this time.

All interviews were conducted using a flexible semi-structured interview guide (available from the authors upon request). The interview guide covered six areas of questions that explored: (a) participants' practice histories (e.g., Please describe your practice and how you came to have a focus on working with LGBT communities); (b) how participants enhanced their practices to meet the needs of LGBT clients (e.g., Have you done any specific training or learning to help you develop your practice in this area?); (c) mental health service access barriers for LGBT populations (e.g., What do you think are the key challenges faced by LGBT people in trying to access supportive mental health services?); (d) factors perceived to increase access for LGBT populations (e.g., What do you think makes it easier for individuals to access your services that might not be true of other services?); (e) the pathways that LGBT communities are thought to take in accessing services (e.g., What services have clients generally accessed prior to seeking care from you?); and (f) recommended changes to the mental health system (e.g., Based on your experiences with your clients, what about the mental health system needs to change provincially?).

\section{Data Analysis}

Consistent with a descriptive phenomenological approach, the data were coded in an iterative process in which transcripts were read and re-read throughout the analysis by two independent researchers (one undergraduate psychology student and one medical student) as new questions and connections were identified (Starks \& Brown Trinidad, 2007). To summarize, we first identified statements and phrases that were repeated or otherwise given particular significance by participants from the interview transcripts (for example, "cost of services" and "medical model" were phrases identified in this stage of the analysis). These significant statements and phrases were re-read and considered in the context of the entire interview transcript in order to establish a preliminary set of themes (e.g., "organizational practices and resources" was a theme identified at this stage). This preliminary set of themes was then reviewed with the research team members.

After this review and discussion, the analysts re-read the interview transcripts in order to identify relationships between the themes identified in the earlier stages of coding and to cluster them into key categories. For example, financial facilitators and barriers, quantity of services, provider education and systemic considerations were grouped together under a meta-theme of systems-level barriers. The resulting thematic framework was a flexible guideline that the analysts progressively revised through discussion and continuous comparison of transcripts. Ultimately, they developed a unified coded dataset.

Following the coding procedure, the text organized under each code was reviewed and summarized by an analytic memo written to capture the major issues. Coding was facilitated by the use of the text management software QSR NVivo8. Techniques to ensure trustworthiness or rather the "truth value" of the research findings included: (a) member checking (the interviewer checked back with participants to ensure accurate understanding); (b) researcher triangulation (two investigators independently read and coded the transcripts); and (c) periodic discussions with the research team of emergent themes and interpretations (Erlandson, Harris, Skipper, \& Allen, 1993; Lincoln \& Guba, 1985). 


\section{RESULTS}

Three major themes emerged from the analysis of participant interviews: (a) client-level barriers; (b) provider-level barriers; and (c) systems-level barriers. In the present analysis, we focus on the systemslevel barriers, within which we identified three sub-themes: (a) barriers inherent in the medical model; (b) availability of supportive services; and (c) disincentives for LGBT-positive providers. Participant recommendations on strategies to improve barriers included in the three sub-themes are then provided.

\section{Barriers Inherent in the Medical Model}

Several participants identified the medical model as a fundamental cause of many problems within the mental health system - not just for LGBT people, but for psychiatric consumers of all sexual orientations and gender identities. The primary limitation of the medical model, as perceived by participants, is the extent to which it diminishes the individuality of mental health care. Participant responses suggest that this diminishment of individuality is inherent in the medical model because of its implicit assumptions that, regardless of the unique and diverse context of individuals, similar symptoms are produced by similar causal factors and, therefore, will respond to similar therapeutic approaches. Thus, participants indicated the medical model may ignore the unique social context of LGBT people seeking mental health services:

I think the medical model does everybody a disservice because it makes everybody not be an expert of their own experience.... There's this emphasis on interpreting other people's experiences for them. (Priya, psychotherapist)

Because if we are very rigid in terms of the modality that we use or that we think is important there is going to be a huge number of people that aren't going to get what they need in terms of coming to counselling. (Susan, social worker)

However, one provider suggested that the tendency of standardized practices as determined by the medical model results in providers often overlooking the social contexts of sexual and gender minority people:

Particularly for trans people the level of ignorance is still pretty mind-boggling... "Oh, well whatever it is that you're struggling has to be because you're trans," but it has nothing whatever to do with being trans or being trans may be a minor chord in there somewhere but it's really a small part in what's going on. (Alak, psychotherapist)

Providers indicated that the lack of knowledge about LGBT people and their experiences in the mental health system can be attributed to poor training models for mental health service providers:

I can tell you that there really wasn't so much LGBT focus at any point in my training, whether it be medical school or residency training. So that definitely is a problem, that people may or may not have had any training at all. (Leah, psychiatrist)

\section{Availability of Supportive Services}

Participants suggested that the current availability of supportive mental health services for the LGBT communities is insufficient to meet the demand for such services. They noted that the extent of available

services was inherently linked to the amount of mental health care funding available. One indicator of the 
lack of supportive services described by participants is the time delay between an individual's attempt to access service and when they receive care:

When people are ready for assistance, like they've actually had the balls to pick up the phone and say "please help me," when the person on the other end is like "sure, in 4 months"-we've lost them. (Philip, social worker)

Although wait lists are a problem in the general mental health system, provider responses suggested that the problem appears to be amplified for LGBT individuals, given that there are fewer available services that are known or presumed to be LGBT supportive.

Many community agencies and other publicly funded programs attempt to mitigate the long wait times resulting from the high demand for LGBT-positive and affordable mental health services through the provision of short-term mental health services. Unfortunately, participants indicated that there is less time available to consider the implications of the social contexts as related to mental health concerns expressed by LGBT people:

The waiting lists are ludicrously long and when you get in [to therapy] you can only be in for a ludicrously short time.... If I'm really struggling with depression this is not something you can fix in 12 sessions. It's not like that. (Alak, psychotherapist)

Participants suggested that supportive mental health services are more available in the private sector than in the public sector. The lack of accessible and appropriate publicly funded services may be particularly problematic for LGBT communities given epidemiological data demonstrating that, on average, LGBT people are of a lower socio-economic status than their heterosexual counterparts (Berg \& Lien, 2002; Trans PULSE, 2010).

At all of the [services] that are accessible, people can be waiting up to a year to get treatment. So there does become a class issue in terms of who can get access when. If you've got money to pay privately that's great, there are a number of us in private practice that can take people quickly. But we know that LGBT communities on the whole make less than our heterosexual and cisgendered counterparts. (Tamara, psychologist)

It was indicated that LGBT individuals who cannot afford to pay for private sector services may be limited to psychiatric services since these are typically covered by provincial health insurance. Participants in this study suggested that psychiatry, as a discipline, is predominantly informed by the medical model, and therefore psychiatric practitioners may be less likely than practitioners of other professional disciplines to feel prepared to address the social context of LGBT people's mental health concerns.

One provider noted that HIV-positive LGBT people have less difficulty receiving supportive mental health care, as there are more resources available. This is congruent with the emphasis of the medical model, as HIV also has somatic consequences:

Obviously if you have HIV there are a lot of resources there. But if you don't and you're from the LGBT community the resources are not as available. (Miguel, psychiatrist)

\section{Disincentives for LGBT-positive Providers}

Most often, the scarcity of services is only considered within the context of its effect on people using mental health services, yet participants in our study emphasized the enormous impact it also has on mental 
health providers. Working conditions for LGBT-competent mental health service providers are an important determinant of access to services for LGBT people, especially considering the reduced retention rates of LGBT-affirmative providers discussed by participants:

Services we provide at [Organization] are terrific and I know people who work there and they are being alarmingly overworked. Those people are going to burn out. They're being asked to work at a kind of intensity that no one can sustain. (Alak, psychotherapist)

Although large caseloads are experienced by practitioners throughout the medical field, participant responses suggest that this may disproportionately affect LGBT-affirmative services due to the dearth of funding available for such services. Participants described substantial pressure on both organizations and providers as a result and highlighted the impact of these burdens on their career choices:

Many of us exit [the public medical model] system because it's a frustrating system for us to work within. It has many constraints ... if you don't buy into that it's pretty hard to work in those places ... it's hard to stomach some of the bureaucratic things that are required in those kinds of places. (Priya, psychotherapist)

In addition to the workload pressures, there are also increased pressures to produce results for clients within a short time frame due to limited resources, when a short time frame may be unrealistic. Organizational practices designed to improve efficiency of services were perceived by participants to place a heavy burden on service providers, as illustrated by the following example:

[At agency X] if as a therapist you haven't created X points of change [on a standardized assessment form] in your clients in 3 sessions -3 sessions! - then it means you're doing something wrong. And these statistics are put up in the staff room so we can have therapists competing against each other to see who can be doing a better job. This is a direct application of salesmanship to psychotherapy. (Alak, psychotherapist)

\section{Recommendations}

Given the novel perspective gained from LGBT-affirming and experienced providers, the following recommendations were made by participants that highlight the significance of our data:

1) Incorporating a blended mental health model

I think that anti-oppression needs to be a lens that is used more widely in mental health. (Priya, psychotherapist)

Several providers discussed the importance of an anti-oppression approach to working with LGBT people in relation to mental health and suggested that an anti-oppression approach would facilitate access to supportive care. An anti-oppression approach addresses social division and structural inequalities through a person-centred philosophy — an area that providers suggest is lacking with the medical model. It focuses both on process and outcome in an effort to empower service users by reducing the potential negative effects of systemic regulations and structural barriers (Dominelli, 2002).

2) Creating more inclusive funding models

My ideal would be that certain other mental health workers, for example, social work, psychology, and sometimes those are the people who are more qualified to do certain kinds of work than the psychiatrist, would be covered.... Depending on the person, they need different kinds of services and those services are not necessarily best provided by the psychiatrists, which usually is the only mental health professional that's covered by OHIP. (Leah, psychiatrist) 
As this excerpt suggests, an anti-oppressive approach to providing mental health services to LGBT communities would consider the structural barriers to service access associated with public health insurance — which provides only minimal and select coverage of mental health care (e.g., psychiatric services). As participants indicated, the cost of non-psychiatric private practice may act as a significant structural barrier for some LGBT people. Consequently, participants recommended expanding OHIP coverage to include a range of LGBT-positive services (e.g., those provided by social workers and community-based programs) that may be more likely to use a social determinants of health approach that considers the impact of social discrimination on the mental health and well-being LGBT people.

3) Increasing support for LGBT affirming mental health providers

I have a wonderful peer supervision group without which I could not function for a second.... "Here's the situation. My dear colleagues, tell me what to do, I have no idea." It would be really impossible to function without the wise guidance of that group of fellow queers who are negotiating the same things themselves. (Alak, psychotherapist)

Participants who identified as private practitioners were more likely to discuss the benefits of a peer supervision group to provide support in addressing client needs or difficult situations within their LGBT practice. They suggested that peer supervision groups would: (a) help to alleviate their sense of isolation from other mental health care professionals; (b) support their work with concerns and issues specific to LGBT communities; and (c) incorporate non-medical model approaches. In addition, they believed that peer supervision groups would provide increased support for mental health service providers in the private sector, thereby improving working conditions and helping to prevent provider burnout.

\section{DISCUSSION}

This study explored barriers to mental health services access for LGBT communities by conducting in-depth interviews with mental health providers in the GTA. The perspectives of the key informant mental health providers who participated in this study have helped to identify three important systems-level barriers to supportive mental health care for members of LGBT communities: (a) limitations of the medical model; (b) availability of supportive services; and (c) disincentives for established LGBT-positive providers.

\section{Limitations of the Medical Model}

For the most part, mental health services are governed by the medical model, which seeks to standardize mental health care provision in an effort to ensure consistent and effective care for all individuals (Engel, 1977; Carpenter, 2002). The medical model classifies all disease as being related to measurable somatic deviations and does not allow for the consideration of social, psychological, or behavioural factors. The medical model is often critiqued for its neglect of human diversity among individuals - particularly with respect to mental health - because it results in service providers attending less to the diverse subjective experiences of people as clients/patients (including the social context of their lives) while privileging a primary focus on objective notions of disease and associated symptoms (Engel, 1977; Carpenter, 2002).

Critics have argued that the widespread implementation of the medical model is particularly problematic for marginalized groups, such as LGBT communities, for two key reasons: (a) because an adherence to the 
medical model results in standardized practices and interventions based on the experiences of a dominant and normative group in society, the experience of marginalized communities are often excluded (Engel, 1977; Carpenter, 2002); and (b) the medical model typically neither accounts for nor responds to the impact of the social context of an individual's life and social determinants of health and well-being. For example, the significant impact of social discrimination-including homophobia, biphobia, and transphobia - experienced by LGBT people may not be taken up by practices and interventions governed by the medical model (Engel, 1977; Carpenter, 2002). Conceivably, mental health issues related to minority stress may be misinterpreted by mental health service providers as resulting from an individual's sexual and/or gender identity itself rather than from homophobia, biphobia, and transphobia. This issue is further exacerbated by the lack of LGBT-specific training available to service providers (Rutherford, McIntyre, Daley, \& Ross, 2012).

\section{Availability of Supportive Services}

The priorities of the medical model translate into a funding model for mental health services that is biased towards coverage of medicalized forms of therapy. The current funding model does not provide sufficient financial support for LGBT-affirmative mental health services. This results in a scarcity of supportive LGBT services, creates an environment with significant wait times for service, and - in an effort to attend to more individuals - leads to time limitations being imposed on courses of treatment. Many individuals who are unable to wait up to a year for mental health treatment would naturally want to turn to the private sector-which offers care that many would not be able to afford. Unfortunately, public health insurance plans, such as OHIP, only cover psychiatrists in private practice - inherently medicalized professionals who are less likely than other providers to address the social context of LGBT people's concerns, including experiences of discrimination. As such, the current funding model has created a system where LGBT individuals must wait too long for services, access services that may not be fully responsive to their experiences, or forfeit services all together.

\section{Disincentives for Established LGBT-positive Providers}

The mental health system also places undue pressures and expectations upon mental health providers, thereby creating further difficulties for LGBT-positive services. Providers are overworked because of the existence of considerable wait times. The stresses of being overworked are aggravated by a mandate to standardize treatment times, which can prevent practitioners from providing adequate care and follow up. The context of working within such a frustrating system has led to participants' suggestions that there may be limited retention rates of LGBT-positive providers. There is already a desperate need for the recruitment of more LGBT-affirming mental health service providers to address the existing mental health needs of LGBT communities; clearly, the risk of limited retention of existing providers is a substantial concern.

The key findings of this study are consistent with previous research on the mental health service experiences of LGBT people. Despite limited research connecting these experiences to the mental health system as a whole, the message is consistent: adequate services (i.e., those that recognize and address the unique social determinants of LGBT mental health) for LGBT communities are minimal (Avery et al., 2001; Israel et al., 
2007; Burckell \& Goldfried, 2006). Furthermore, Project Affirmation, a published study by the Coalition of Lesbian and Gay Rights in Ontario (CLGRO) emphasizes that two of the most significant barriers facing LGBT communities are poor training of mental health care professionals (due to lack of funding) and overt oppression — both of which are influenced by the medical model (CLGRO, 1997). This study was produced about 15 years ago and there have been important local innovations in promoting LGBT training among service providers; nonetheless, our participants suggest that providers continue to lack formal education and training in this area.

\section{Contextual Perspective}

Overall, several of the barriers described in the results section of this paper are problems that may be inherent in the mental health system as a whole, but that may also have a different and significant impact on LGBT communities due to the scarcity of LGBT-competent mental health services that are responsive to the social context impacting the mental health of LGBT people. A study of barriers to Ontario mental health services indicated that often people are not always sure where to go for services and are not convinced that services will be helpful (Jitender, et al., 2007). Based on participant responses, it may be likely that members of LGBT communities may experience these same barriers in addition to barriers associated with heterocentric and genderist mental health services. Consequently, LGBT people may face the additional burden of trying to get information about which mental health services will be most likely to be responsive to their LGBT-specific concerns. An additional common barrier among communities is difficulty getting an appointment in a timely manner. This is often due to the scarcity of mental health services generally, thus resulting in long wait lists and short-term therapy (Jitender, et al., 2007). Although this is a difficulty across the mental health system, LGBT people may experience particular difficulty accessing timely service as there are significantly fewer services that are LGBT-specific or explicitly LGBT-positive.

It should be noted that LGBT communities are not the only communities that are adversely and disproportionately affected by identified barriers in the mental health system. Research conducted on the service access experiences of diverse racial minority and cultural groups in Canada identify similar barriers as those described above. Similarities include the limited number of programs and/or approaches that reflect and respond to the specific needs of racial minority and cultural communities including, for example, the lack of culturally competent mental health providers (Centre for Addiction and Mental Health, 2003; Williams, 2001). While it is also important to recognize historical differences between racial and sexual and gender minority communities in relation to the mental health system and systemic oppressions, the identification of similar service access barriers may be indicative of the overarching impact of the medical model in mental health service planning (Williams, 2001). The very little focus that the medical model places on the social context (e.g., racism, homophobia) in relation to understandings of mental health and associated treatments may lead to similar system-level barriers for racial and sexual and gender minority communities (Centre for Addiction and Mental Health, 2003; Kafele, 2004). As our participants suggested, the research literature on the mental health service access experiences of racial minority communities also recognizes the importance of developing anti-oppression frameworks of service delivery to better address the mental health concerns of these populations (Kafele, 2004). 


\section{Limitations}

Despite logical similarities in our results with those of previous research, it is important to note some limitations of this study. Our participants are all located in the GTA, a relatively progressive and wellresourced location with respect to mental health services for LGBT communities. It is, therefore, difficult to generalize our findings to other locations. These barriers may be magnified in locations that are less resourced; alternatively, they may offer some insight into future challenges for service settings that are currently grappling with how to provide LGBT-specific services. Discussions regarding funding structure may also be limited to Ontario, as public funding of health services may significantly differ from the structure of other provincial funding models. Another limitation is that our sample size of eight participants likely did not result in theoretical saturation. This indicates a need to conduct further research, in order to ensure all themes are explored fully. Furthermore, we were unable to identify any heterosexual LGBT-affirmative providers who met our inclusion criteria and we achieved only limited diversity in participant race/ethnicity. Finally, while this study focused on counselling-based professional disciplines, we recognize that the inclusion of other disciplines (i.e., nurses and/or in-patient psychiatrists) would be worthy of additional study.

\section{SUMMARY}

In summary, our data support three key recommendations for changes to the mental health system: (a) incorporating alternative approaches to mental health care (including an anti-oppression approach) into the medical model; (b) expanding the inclusivity of the OHIP funding in the private sector; and (c) creating further incentives for LGBT-focused mental health professionals to engage in LGBT-specific training and careers. The medical model has limitations within mental health care that specifically affect LGBT communities. As such, the inclusion of alternative models (i.e., those based on the social determinants of health) that give greater consideration to social context may therefore lead to improved supportive services for LGBT communities. Additionally, broadening the funding reach of OHIP to all mental health professionals in the private sector would give greater opportunity for LGBT individuals to access social workers and psychologists who may be better suited to addressing their experiences. This could also lead to a decrease in wait times and limitations on treatment schedules, as more options would be available to access supportive mental health services. Finally, incentives to improve opportunities for those seeking careers in LGBT mental health care would help mitigate the impact of current systems-level induced pressures_-potentially leading to increased retention and recruitment rates. These recommendations represent novel approaches to reducing systems-level barriers; however, our data also indicate a need for further research on provider-level and client-level barriers influencing access to supportive mental health services.

\section{RÉSUMÉ}

Les lesbiennes, les gais, les personnes bisexuelles et transgenres (LGBT) rapportent un état de santé mentale plus pauvre que les personnes hétérosexuelles et cisgenres (non trans). Cependant, on connaît peu leurs expériences avec les services de santé mentale. Dans cette étude qualitative, 8 fournisseurs de services de santé mentale ayant une expérience substantielle avec les communautés LGBT ont été interviewés afin d'amorcer l'examen des barrières systémiques dans l'accès à des services de santé mentale qui apportent du soutien aux personnes LGBT. Les résultats suggèrent que le modèle médical, dominant dans le système de 


\section{SYSTEMS-LEVEL BARRIERS IN ACCESSING SUPPORTIVE MENTAL HEALTH SERVICES}

santé mentale, produit des barrières particulières d'accès pour les LGBT. Nous proposons des recommandations pour abaisser ces barrières, dont l'implantation d'une approche anti-oppression en santé mentale.

Mots clés : lesbienne/gai/bisexuel/bisexuelle/transgenre, services de santé mentale, barrières au niveau du système, modèle médical, approche anti-oppression

\section{NOTE}

1. Genderist: A belief system that holds people to traditional expectations based on gender, or punishing or excluding those who don't conform to traditional gender expectations.

\section{REFERENCES}

American Psychiatric Association. (1973). Homosexuality and sexual orientation disturbance: Proposed change in DSM-II, 6th printing, page 44. Position statement (retired). Reference no. 730008.

Avery, A.M., Hellman, R.E., \& Sudderth, L.K. (2001). Satisfaction with mental health services among sexual minorities with major mental illness. American Journal of Public Health, 91(6), 990-991.

Berg, N., \& Lien, D. (2002). Measuring the effect of sexual orientation on income: Evidence of discrimination. Contemporary Economic Policy, 20(4), 394-414.

Brotman, S., \& Ryan, B. (2004). An intersectional approach to queer health policy and practice: Two-Spirit people in Canada. Canadian Diversity, 3(1), 59-64.

Burckell, L.A., \& Goldfried, M.R. (2006). Therapist qualities preferred by sexual-minority individuals. Psychotherapy: Theory/Research/Practice/Training, 43(1), 32-49.

Carpenter, J. (2002). Mental health recovery paradigm: Implications for social work. Health \& Social Work, 27(2), 86-94.

Centre for Addiction and Mental Health. (2003). Building bridges, breaking barriers access project: Final report (pp. 2-42). Toronto, ON: Ontario Human Rights Commission.

Clark, R., Anderson, N.B., Clark, V.R., \& Williams, D.R. (1999). Racism as a stressor for African Americans: A biopsychosocial model. American Psychologist, 54, 805-816.

Clements-Nolle, K., Marx, R., Guzman, R., \& Katz, M. (2001). HIV prevalence, risk behaviours, health care use and mental health status of transgender persons: Implications for public health intervention. American Journal of Public Health, 91(6), 915-921.

Coalition for Lesbian \& Gay Rights in Ontario (CLGRO). (1997). Systems failure: A report on the experiences of sexual minorities in Ontario's health-care and social-services systems: The final report of Propect Affirmation. Toronto, ON: Author. Retrieved from http://www.clgro.org/pdf/Systems_Failure-Report.pdf

Crisp, C., \& McCave, E.L. (2007). Gay affirmative practice: A model for social work practice with gay, lesbian and bisexual youth. Child Adolescent Social Work Journal, 24, 403-421.

Daley, A. (1998). Lesbians in health care: Heterosexual hegemony and strategies for change. Canadian Social Work Review, 15(1), 57-71.

Davies, D. (1996). Towards a model of gay affirmative therapy. Pink therapy: A guide for counsellors and therapists working with lesbian, gay and bisexual clients (pp. 24-40). Philadelphia, PA: Open University Press.

Dobinson, C., MacDonnell, J., Hampson, E., Clipsham, J., \& Chow, K. (2005). Improving the access and quality of public health services for bisexuals. Journal of Bisexuality, 5(1), 39-78.

Dominelli, L. (2002). Anti-oppressive practice in context. In R. Adams, L. Dominelli, \& M. Payne (Eds.), Social work: Themes, issues and critical debates (2nd ed.) (pp. 3-19). Basingstoke, UK: Palgrave.

Duncan, K., Clipsham, J., Hampson, E., Krieger, C., MacDonnell, J., Roedding, D., . . Milne, D. (2000). Improving the access to and quality of public health services for lesbians and gay men (Position paper). Toronto, ON: Ontario Public Health Association.

Engel, G.L. (1977). The need for a new medical model: A challenge for biomedicine. Science, 196, 129-136.

Erlandson, D., Harris, E., Skipper, B., \& Allen, S. (1993). Doing naturalistic inquiry: A guide to methods. Thousand Oaks, CA: Sage.

Gapka, S., \& Rupert, R. (2003). Trans health project (Position paper). Toronto, ON: Ontario Public Health Association. 
Israel, T., Gorcheva, R., Burnes, T.R., \& Walther, W.A. (2007). Helpful and unhelpful therapy experiences of LGBT clients. Psychotherapy Research, 18(3), 294-305.

Jackson, B., Daley, A., Moore, D., Mulé, N., Ross, L., \& Travers, A. (2006). Whose public health? An intersectional approach to sexual orientation, gender identity and the development of public health goals for Canada (Discussion Paper submitted to Health Canada). Toronto, ON: Rainbow Health Network (RHN)/Coalition for Lesbian and Gay Rights in Ontario (CLGRO). Retrieved from http://www.rainbowhealthnetwork.ca/files/whose_public_health.pdf

Jitender, S., Jagdeo, A., Cox, B.J., Clara, I., ten Have, M., Belik, S., . . Stein, M.B. (2007). Perceived barriers to mental health service utilization in the United States, Ontario and the Netherlands. Psychiatric Services, 58(3), 357-364.

Kessler, R.C., Mickelson, K.D., \& Williams, D.R. (1999). The prevalence, distribution and mental health correlates of perceived discrimination in the United States. Journal of Health and Social Behaviour, 40, 208-230.

King, M., et al. (2008). A systematic review of mental disorder, suicide, and deliberate self harm in lesbian, gay and bisexual people. BMC Psychiatry, 8, 70-87.

Kafele, K. (2004). Racial discrimination and mental health: Racialized and aboriginal communities. Ontario Human Rights Commissioner Race Policy Dialogue Conference Paper. Toronto, ON: Ontario Human Rights Commission.

Lincoln, Y., \& Guba, E. (1985). Naturalistic inquiry. New York, NY: Sage.

MacDonnell, J.A. (2001a). Educational needs perceived by expectant lesbian couples. Unpublished master's thesis, Brock University, St. Catharines, ON.

MacDonnell, J.A. (2001b). Facilitating support for expectant lesbians in a public health context: Encountering resistance in the research process. Journal of the Association for Research on Mothering, 3, 109-120.

Mathieson, C., Bailey, N., \& Gurevich, M. (2002). Health care services for lesbian and bisexual women: Some Canadian data. Health Care for Women International, 23, 185-196.

Mays, V.M., \& Cochran, S.D. (2001). Mental health correlates of perceived discrimination among lesbian, gay, and bisexual adults in the United States. American Journal of Public Health, 91(11), 1869-1876.

Meyer, I.H. (2003). Prejudice, social stress, and mental health in lesbian, gay, and bisexual populations: Conceptual issues and research evidence. Psychological Bulletin, 129(5), 674-697.

Page, E.H. (2004). Mental health services experiences of bisexual women and bisexual men. Journal of Bisexuality, 4(1), 137-160.

Pitts, M.K., Couch, M., Mulcare, H., Croy, S., \& Mitchell, A. (2009). Transgender people in Australia and New Zealand: Health, well-being and access to health services. Feminism \& Psychology, 19(4), 475-495.

Rutherford, K., McIntyre, J., Daley, A., \& Ross, L.E. (2012). Development of expertise in LGBT mental health service provision: A qualitative study. Medical Education, 12.

Simeonov, D., Steele, L.S., Anderson, S., \& Ross, L.E. (2011). Perceived satisfaction with mental health services in the lesbian, gay, bisexual, transgender and transsexual communities in Ontario, Canada: An internet-based survey. Manuscript submitted for publication.

Spitzer, R.L. (1981). The diagnostic status of homosexuality in DSM-III: A reformulation of the issues. American Psychiatric Association, 138, 210-215.

Starks, H., \& Brown Trinidad, S. (2007). Choose your method: A comparison of phenomenology, discourse analysis, and grounded theory. Qualitative Health Research, 17(10), 1372-1380.

Tjepkema, M. (2008). Health care use among gay, lesbian and bisexual Canadians. Health Reports, 19(1), 53-64.

Trans PULSE. (2010). Who are trans people in Ontario? Trans Pulse E-Bulletin, 1(1), 1-2.

Williams, C.C. (2001). Increasing, accessing and building equity into mental health services: An examination of the potential for change. Canadian Journal of Community Mental Health, 20(1), 37-51. 